\title{
The best in all possible worlds? A quantitative genetic study of geographic variation in the meadow vole, Microtus pennsylvanicus
}

\author{
Thomas F. Hansen and Rudy Boonstra
}

\begin{abstract}
Hansen, T. F. and Boonstra, R. 2000. The best in all possible worlds? A quantitative genetic study of geographic variation in the meadow vole, Microtus pennsylvanicus. Oikos 89: 81-94.
\end{abstract}

\begin{abstract}
The meadow vole, Microtus pennsylvanicus, is the most widely distributed Microtus species in North America. Across its range, it shows marked demographic differences, experiences a large range of climatic conditions, and varies considerably in body size and life-history characteristics. To study the genetic basis of the geographic variation in size and life history of this species, we subjected three populations, one from central Canada and two from eastern Canada, to quantitative genetic analysis in the lab. We studied the variance and covariance of several size and growth variables as well as age and size at maturity by means of population crosses, full-sib analysis, and parent-offspring regressions. We found that the phenotypic differences among these populations are almost entirely due to environmental effects. However, within populations, additive genetic and maternal effects explain most of the variation. We discuss possible explanations for the lack of genetic differences among the populations and speculate that a similar reaction norm is maintained in all populations through heterogeneity in the temporal or spatial environment that the populations experience. The heterogeneity may be mediated through population density fluctuations, climatic variation, or variation in site productivity. Thus, we hypothesize that $M$. pennsylvanicus has evolved to be the best in all possible worlds rather than in one actual world. This study highlights the crucial importance of maternal and environmental effects on the size, growth, and life history of small rodents.
\end{abstract}

T. F. Hansen, Dept of Biology, Div. of Zoology, Univ. of Oslo, P.O. Box 1050, Blindern, N-0316 Oslo, Norway (thomas.hansen@bio.uio.no). - R. Boonstra, Div. of Life Sciences, Univ. of Toronto at Scarborough, 1265 Military Trail, Scarborough, ON, Canada M1C $1 A 4$.

Most widely distributed species show considerable geographic variation in size and life history, and this is traditionally assumed to be genetic in origin and to reflect adaptation to varying local ecological conditions (Mayr 1963). More recently, several empirical studies have questioned whether geographic size variation must always be genetically based. Nongenetic variation on large geographic scales has been convincingly demonstrated in birds (James 1983), lizards (Niewiarowski and Roosenburg 1993, Sorci et al. 1996) and rodents (Patton and Brylski 1987, Yoccoz et al. 1993). These results do not necessarily mean that the observed size differences are not adaptive. We do not expect large nonadaptive or maladaptive differences in body size due to the strong correlations which exist between size and many important life-history traits. Rather, the findings point to the importance of phenotypic size plasticity in producing local adaptation.

In this study we investigate the quantitative genetic basis for regional size variation in the meadow vole, Microtus pennsylvanicus (Rodentia, Muridae). Small rodents in general and voles in particular are excellent and challenging organisms for studying the ecology and evolution of size as they show size variation on so many different axes. There are well-documented reaction norms of size with respect to season, photoperiod, temperature, food availability, population density and maternal condition (see discussion). Considerable re-

Accepted 7 July 1999

Copyright (C) OIKOS 2000

ISSN 0030-1299

Printed in Ireland - all rights reserved 
gional differences are also commonplace, including size increases on islands (Foster 1964, Lomolino 1985, Adler and Levins 1994, Berry 1996) and responses to climate. In some cases the climatic response in rodents follows Bergmann's "rule", that endothermic animals get larger with latitude and elevation (Mayr 1963, but see McNab 1971, Geist 1987). Examples include woodrats, Neotoma (Brown and Lee 1969, Smith et al. 1995), house mice, Mus domesticus (Lynch 1992, 1994), and voles as a guild (Ralls and Harvey 1985), but the meadow vole gets smaller with increasing latitude (McNab 1971). Snell and Cunnison (1983) examined skullsize variation of meadow voles across a geographic range from northeastern US to Alaska and found that the best predictor of small size was extreme low winter temperature.

Body size is a very important determinant of life-history variation in mammals. Key life-history traits such as age at maturity, annual fecundity, litter size, offspring size, mortality and longevity all show allometric dependence on adult size and a substantial amount of the variation across species can, at least statistically, be accounted for by variation in size (Charnov 1993). The evolutionary basis of these relationships is under constant debate (Harvey et al. 1989), but there is little doubt that size must play an essential role in life-history evolution. Recent work shows how many aspects of life-history variation in mammals can be predicted from models where body size or some closely related variable are optimized (Charnov 1993, Kozlowski and Weiner 1997). This raises the possibility that life-history adaptation may be achieved through simple adjustments of size and growth. This seems particularly likely as a mechanism behind adaptive differences between closely related local populations, as more complex adjustments of the life history may be difficult to produce rapidly. On this view, body size in any local population is expected to spend most time under stabilizing selection around an optimum determined by complex trade-offs among the many life-history variables that depend on size, and geographic size variation becomes a reflection of geographic variation in optimal life-history strategies.

Undoubtedly, geographic size variation in rodents often has a genetic basis that may reflect regional adaptation. Several studies have found that geographic size differences between populations are maintained in a laboratory setting (Hansson 1985, Mattingly and McClure 1985, Roth and Klein 1986, Ebenhard 1990, Lynch 1992, Ims 1997). However, this is not a universal pattern, and there are also examples of nongenetic differences (Patton and Brylski 1987, Yoccoz et al. 1993, this study). Indeed, the relative plasticity of size in voles with respect to a number of environmental variables, such as temperature, food availability and population density, predicts nongenetic geographic size variation. However, due to the close linkage of size to fitness through life-history traits, such variation will be actively opposed by selection unless the reaction norms are in fact producing adaptive variation also on the geographic scale. Hence, just as reaction norms generate nongenetic adaptive variation within local populations, they may also be expected to do so on large spatial scales.

The meadow vole is the ubiquitous 'field mouse' of North America, occurring all the way from Georgia, throughout northern and eastern United States, throughout Canada from Newfoundland to British Columbia and on into the Yukon and Alaska. This geographical range encompasses a range of temperatures, seasonality, habitats, food plants, and communities of competitors and predators. There are also large variations in population density and demographic patterns (Krebs et al. 1973, Krebs and Wingate 1985, Mihok et al. 1985, Taitt and Krebs 1985). In this paper we explore the quantitative genetic basis of the geographic size and life-history variation among geographically distinct populations, and compare it with quantitative genetic variation within local populations. We study three populations, one island and one mainland population from south-eastern Canada, and one more northern and small-bodied population from a central Canadian site on the edge of the boreal forest. Although there are considerable and area-typical differences among these populations in the field, we provide evidence that there are almost no differences in a common environment. This stands in striking contrast to the within-population variation that is dominated by maternal and additive genetic effects. We hypothesize that the geographic variation is due to different expression within each area of a similar norm of reaction to population density or food availability. Our hypothesis is no more than a biologically motivated speculation, but we hope it can be further tested and provide a challenge to integrate the many facets of vole size variation into one coherent picture.

\section{Materials and study sites}

\section{Source populations}

Pinawa, Manitoba $\left(50^{\circ} 11^{\prime} \mathrm{N}, 96^{\circ} 03^{\prime} \mathrm{W}\right)$ : This site is a 32-ha oldfield at the Whiteshell Nuclear Research Establishment which was trapped between 1968 and 1986 (Mihok et al. 1985, 1988). The population has gone through apparent multiannual cycles lasting 3-4 years, but also periods when the fluctuations are annual. On 10 May 1986, animals were sent from Pinawa, Manitoba to the University of Toronto. These animals were F1 and F2 generations (not inbred) which had been born in the laboratory to field-caught voles obtained in spring 1985 from a decline-phase population (Mihok and Boonstra 1992). They were on average 14 weeks 
old when arriving in Toronto and 20 weeks old when released into the breeding enclosures.

Wolfe Island, Ontario $\left(44^{\circ} 12^{\prime} \mathrm{N}, 76^{\circ} 20^{\prime} \mathrm{W}\right)$ : This 135 $\mathrm{km}^{2}$ island, located at the eastern end of Lake Ontario near Kingston, Ontario, consists of farms, some woodlots and old fields. The nearest distance to the mainland is $3 \mathrm{~km}$, but as the water often freezes during winter, the population is not likely to be completely isolated (Lomolino 1982, 1984). The population has experienced marked declines, especially over the summer breeding season, but it does not seem to show a multiannual cycle. Animals for this study were obtained on 20 May 1986 by live-trapping on the same abandoned pasture as reported in Plante et al. (1989a). They were overwintered animals and thus approximately 32 weeks old. Densities appeared high given the ease of capturing the necessary samples. Additional details of the demography of this population can be found in Boonstra and Boag (1992) and Boonstra et al. (1994).

Toronto, Ontario $\left(43^{\circ} 40^{\prime} \mathrm{N}, 79^{\circ} 38^{\prime} \mathrm{W}\right)$ : This site is a 10-ha grassland adjacent to Pearson International Airport surrounded by highways, but with connecting culverts to about 2000 ha of grasslands beside the runways. The population was trapped between 19781983 and went through one apparent 4-year cycle, but it was not followed long enough to discern if this was a repeatable pattern. The site has been used in other studies and a description of the site and details of the population demography can be found in Boonstra and Rodd (1983), Boonstra (1985), and Boonstra et al. (1994). Animals for this study were obtained by livetrapping from 6-28 May 1986. They were overwintered animals and approximately 32 weeks old. Although there was no population census when the animals were collected, densities appeared high given the ease of capturing the necessary samples.

\section{Climate and productivity at the study sites}

Climatic data for the three sites are given in Table 1. The Pinawa site has a continental climate with moderately short, but warm summers, and cold, severe winters with permanent snow covering the ground from mid-November to April (Mihok 1984). The weather at both Wolfe Island (Kingston) and Toronto is much more moderate than that at Pinawa, being further south and under the influence of Lake Ontario. Winter at Kingston is relatively mild, though slightly more severe than at Toronto with permanent snow cover from mid-December to early March, and the summer is warm. In winter, Pinawa is about $10^{\circ} \mathrm{C}$ colder than the other sites and the most extreme temperatures experienced at all sites are about $20^{\circ} \mathrm{C}$ below the January average. Although the January temperature differences would be less extreme in the subnivean space due to deeper January snow cover at Pinawa, the increased length of winter, much lower temperatures, and lower precipitation at Pinawa makes this site generally much colder than Ontario.

The effective growing season (temperature above $5^{\circ} \mathrm{C}$ ) is approximately $25 \%$ longer at the Wolfe Island and Toronto sites than at Pinawa, and combined with $40-70 \%$ higher annual precipitation, this leads to a much higher primary production at the Ontario sites. Accordingly, peak standing biomass is much higher at the Toronto sites. Autumn standing biomass at Toronto is about $500-700 \mathrm{~g} / \mathrm{m}^{2}$ (Reader pers. comm.), while it is only $200-400 \mathrm{~g} / \mathrm{m}^{2}$ in Pinawa (Mihok pers. comm). Bonser and Reader (1995) found intensity of herbivory to be a direct function of primary productivity, and peak vole densities are accordingly much higher at the Ontario sites (560/ha at Toronto - Boonstra 1985 and 340/ha at Wolfe - Plante et al. 1989a) than at Pinawa (105/ha - Mihok et al. 1985).

\section{Methods}

\section{Field investigations}

To assess how voles from our three areas grew in their home environment, we examined how a representative cohort of overwintering males grew from the onset of the breeding season in spring (defined as that point when at least $50 \%$ of the males were in breeding condition - i.e. scrotal) until most disappeared (only 1-3 individuals remaining). Females were excluded from this analysis because of the effect of pregnancy on body mass. For the Toronto population, we examined

Table 1. Climatic profiles of the three source areas of Microtus pennsylvanicus. All values are averages obtained over the period from 1961-1990 (Canadian Climate Normals 1993), except for snow depth for Pinawa which is obtained from 1968-1978 (Table 2 in Mihok et al. 1985). The weather stations were located as follows: the Pinawa station is at Whiteshell Nuclear Research Establishment adjacent to the field site; the Wolfe data are from Kingston station within 10 $\mathrm{km}$ of the field site; and the Toronto station is at Pearson International Airport adjacent to the field site.

\begin{tabular}{lccc}
\hline Weather variable & Pinawa & Wolfe & Toronto \\
\hline $\begin{array}{l}\text { Mean yearly } \\
\quad \text { temperature (C) }\end{array}$ & $1.9^{\circ}$ & $6.7^{\circ}$ & $7.2^{\circ}$ \\
$\begin{array}{l}\text { Mean min. temp., } \\
\quad \text { January }\end{array}$ & $-23.8^{\circ}$ & $-12.6^{\circ}$ & $-11.1^{\circ}$ \\
$\begin{array}{l}\text { Extreme min. temp., } \\
\text { January }\end{array}$ & $-43.9^{\circ}$ & $-34.5^{\circ}$ & $-31.3^{\circ}$ \\
$\begin{array}{l}\text { Snow depth in } \\
\text { January (cm)* }\end{array}$ & 35.2 & 14.0 & 8.0 \\
$\begin{array}{l}\text { Mean min. temp., July } \\
\text { Degree days above }\end{array}$ & 1665 & 2020 & 2090 \\
$\quad 5^{\circ} \mathrm{C}$ \\
$\begin{array}{l}\text { Yearly precipitation } \\
(\mathrm{mm})\end{array}$ & 558 & 964 & 781 \\
\hline
\end{tabular}

* Snow depth at Pinawa measured on 15 January and at Wolfe and Toronto at month end. 
Table 2. The number of offspring used in the statistical analysis of the breeding experiments (i.e. surviving to weaning). Sire and Dam refer to the parental populations. Litters are counted as the number of litters where at least one offspring of that sex survived to weaning. In total, 45 litters with 126 male and 125 female offspring were analyzed.

\begin{tabular}{|c|c|c|c|c|c|c|}
\hline \multirow[t]{2}{*}{ Cross } & \multirow[t]{2}{*}{ Sire } & \multirow[t]{2}{*}{ Dam } & \multicolumn{2}{|c|}{ Number of males } & \multicolumn{2}{|c|}{ Number of females } \\
\hline & & & Litters & Individuals & Litters & Individuals \\
\hline $\mathrm{T} \times \mathrm{T}$ & Toronto & Toronto & 10 & 34 & 10 & 23 \\
\hline $\mathrm{T} \times \mathrm{P}$ & Toronto & Pinawa & 6 & 9 & 5 & 18 \\
\hline $\mathrm{T} \times \mathrm{W}$ & Toronto & Wolfe & 4 & 10 & 4 & 13 \\
\hline $\mathrm{P} \times \mathrm{T}$ & Pinawa & Toronto & 3 & 12 & 5 & 18 \\
\hline $\mathrm{P} \times \mathrm{P}$ & Pinawa & Pinawa & 7 & 22 & 6 & 10 \\
\hline $\mathrm{W} \times \mathrm{T}$ & Wolfe & Toronto & 9 & 24 & 10 & 27 \\
\hline $\mathrm{W} \times \mathrm{W}$ & Wolfe & Wolfe & 5 & 15 & 5 & 16 \\
\hline
\end{tabular}

the cohort from 1980 (a peak year; initial cohort size $N=43$, Boonstra 1985). For the Pinawa population, we used data from 1970 (a peak year $-N=79$, Mihok et al. 1985). For the Wolfe population, we used data from 1984 and 1986, years in which the initial samples were live-trapped early in spring and sample sizes were reasonable $-N=19$ and 89 , respectively (Plante et al. 1989a, Boonstra et al. 1994). Two years were included in the Wolfe sample because of the rapid disappearance of the 1986 cohort and because we wanted to see if the mass changes were similar from one year to the next. Average weights of these cohorts were calculated for each trapping session. For Toronto and Pinawa, we included only males that were caught at least every four weeks. For Wolfe, all males were included irrespective of how far apart in time they were trapped, because the trapping interval was often greater than four weeks in the summer.

\section{Experimental design}

We made reciprocal crosses between Toronto and Pinawa and between Toronto and Wolfe as well as within-population crosses for the three populations. This yielded seven distinct crosses as reported in Table 2. All animals were held in the laboratory for two weeks prior to pairing to ensure that none of the females had been impregnated in the field. Virtually every Toronto female and two Wolfe females were already pregnant with their first litter when brought into lab and their litters were removed. Animals were then randomly paired to obtain the necessary crosses and introduced into $423-\mathrm{m} \times 3-\mathrm{m}$ field enclosures at the Station for Atmospheric Experiments on the outskirts of Toronto (see Boonstra and Boag 1987 for details of area). Breeding took place in field enclosures because of the great difficulty of breeding meadow voles reliably under laboratory conditions. Each enclosure had a natural turf vegetation, was lined with galvanized sheet metal $(91 \mathrm{~cm}$ wide, half above and half below the ground) with three Longworth live-traps and one snow shelter; each enclosure was fertilized in spring.
Introduction of the pairs into the enclosures took place between 24 May and 28 June 1986. At day 18 and 19 after the pairs were introduced (gestation period is 21 days), the enclosures were trapped and all pregnant animals removed to the laboratory, where they gave birth. Because of the potential effect of litter size on growth of offspring, we tried to standardize the litter size to six by crossfostering babies of about the same age and strain from litters greater than six with litters smaller than six. These cross-fostered young were not included in the subsequent analyses, as they were too few to be used in a cross-fostering analysis. Young were weaned at ca 21 days of age, separated into same-sex groups of three; usually littermates were put together. At approximately weekly intervals until 9-10 weeks of age, the young were weighed and reproductive maturity noted (testes scrotal or abdominal in males; vagina perforate or nonperforate in females). The variation in the time of measurement was usually only 1-2 days and random with respect to crosses. In the laboratory, all animals were maintained on an 18L: 6D light cycle at $20^{\circ} \mathrm{C}$. Water and food (Purina Lab Chow and Purina Rabbit Chow) were provided ad libidum, and lettuce was provided twice weekly. All animals were housed in $48 \times 27 \times 16-\mathrm{cm}$ polypropylene cages on a bedding of hardwood chips and given cotton nesting material. All animals were tagged with fingerling ear-tags.

The measures of size could not be used directly as they were only approximately made on a weekly basis. We used weight at weaning (denoted Wwean) as one variable and from the remaining size measurements we constructed three size variables by interpolation (i.e. assuming three intervals of linear growth after weaning). We computed weight at day 11, 25 and 40 after weaning. These ages were chosen to roughly minimize measurement error by averaging two measures and to ensure that each measurement was used only once. From these we derived growth variables by differencing. We refer to the growth from weaning to day 11 as G11, the growth from day 11 to day 25 as G25 and the growth from day 25 to 40 as G40. In this way we divide the postnatal growth into linear segments as suggested for M. pennsylvanicus by Morrison et al. (1977). We 
used weight at day 40 after weaning (W40) as a measure of adult size. We also analyzed age and weight at maturity (denoted Amat and Wmat, respectively).

\section{Full-sib analysis}

The quantitative genetic analyses follow Lynch and Walsh (1998). For each trait we estimated the mean effects of the seven crosses and used this as a basis for computing the between-population effects. Males and females were analyzed separately.

The population effects can be decomposed as follows

$P_{i j}=P_{A i}+P_{A j}+P_{D i j}+P_{M i}+P_{e i j}+\varepsilon_{i j}$

where $i$ indexes the maternal population and $j$ the paternal population. A subscribed " $A$ " denotes additive effects, a subscribed " $D$ " denotes dominance effects, a subscribed " $M$ " denotes maternal effects and a subscribed " $e$ " denotes epistatic and environmental effects. The residual error $\varepsilon_{i j}$ is modeled as a within-population effect as discussed below. We always included a fixed effect for each of the seven crosses. From estimates based on this model we derived estimates of the three additive effects, two interaction effects (Toronto by Pinawa and Toronto by Wolfe) and two contrasts between maternal effects (Toronto - Pinawa and Toronto - Wolfe). These derived estimates assume that the nonadditive effects are similar in the three populations.

The residual variance can be divided into a betweenlitter component and a within-litter component. Assuming random mating, linkage equilibrium and outbred parents, the between-litter component, $\sigma_{b l}^{2}$, and the within-litter component, $\sigma_{w l}^{2}$, can be decomposed into

$\sigma_{b l}^{2}=\sigma_{c}^{2}+\sigma_{m}^{2}+\sigma_{A}^{2} / 2+\sigma_{D}^{2} / 4+\sigma_{A A}^{2} / 4+\ldots$,

$\sigma_{w l}^{2}=\sigma_{e}^{2}+\sigma_{A}^{2} / 2+3 \sigma_{D}^{2} / 4+3 \sigma_{A A}^{2} / 4+\ldots$,

where $\sigma_{c}^{2}$ is the variance due to cage environment, $\sigma_{m}^{2}$ is the variance due to maternal effects, $\sigma_{A}^{2}$ is the additive genetic variance, $\sigma_{D}^{2}$ is the dominance variance, $\sigma_{A A}^{2}$ is the additive $\times$ additive variance, and higher-order epistatic effects are not specified. The parameter $\sigma_{e}^{2}$ incorporates measurement error and environmental effects specific to the individual. It is obvious that we cannot derive all potentially relevant variance components from estimates of only $\sigma_{b l}^{2}$ and $\sigma_{w l}^{2}$, but by making various assumptions, comparing crosses and comparing with results from parent-offspring regressions (see below), we will be able to construct a picture of the sources of variation in the populations.

Technically, the maternal effect in this model is a parental effect, but as offspring were reared in isolation from their fathers, it can be assumed that the fathers did not contribute anything but their genes. In contrast to some other Microtus, paternal care is unusual in $M$. pennsylvanicus (McGuire and Novak 1984).

We fitted a series of different models to the variance structure. These included models with covariances between some of the traits (see below), models with different between- and within-litter components for each cross, and models where the variances were assumed to be the same in the different crosses. Apart from the unlikely possibility that these populations constitute a unified panmictic population, there is little reason to expect their variance components to be the same. However, estimation of large numbers of variance components could not be done with great precision and, AIC (defined below) was used to pick the most economical representation. The estimates of the fixed effects (i.e. between-population effects) are not very sensitive to the fitted variance structure, but their standard errors may be. Based on AIC it was always optimal to assume that all crosses had the same variance components. We emphasize that this should not be taken as strong evidence for similarity of variances as the power to detect differences is relatively weak. The proper interpretation of the reported within population variances is thus that they are weighted averages over the three populations.

We ended up estimating weight at weaning (Wwean) and the growth traits (G11, G25, G40) in a joint multivariate analysis where their within-population covariances were taken into account. Weight at day 40 (W40) was estimated in a separate univariate analysis, as it is the sum of the previous traits (for each individual). Age and weight at maturity (Amat \& Wmat) were estimated separately in a multivariate analysis (that also included weight at weaning) and only included individuals that did mature before end of the experiment.

\section{Parent-offspring regressions}

To clarify the role of additive genetic and maternal components of variance, offspring traits were regressed on the weight of parents measured at time of breeding and at the end of the experiment. Mothers were neither pregnant nor lactating when these measures were taken. The offspring trait most similar to these parental measurements is weight at day 40 after weaning. We estimate heritability of size as twice the regression of this trait on parent's last weight in lab. This assumes that additive-by-additive epistasis is absent. We use parental last weights as this may reflect an environment more similar to that of the young. As there was little difference between regressions on sire and dam, we base the heritability estimates on son-father and on daughtermother regressions.

For the other traits, the father-offspring regression is better interpreted in terms of additive genetic covari- 
ances between the offspring and parental traits. For all traits, a difference between the maternal and paternal regressions will indicate if there are maternal effects related to the size of the mother. In these regressions we corrected for the correlation of siblings by including litter as a random effect. A cross effect was included in the regression so as to make the regressions estimate within-cross effects, but we assumed that all crosses had the same regression slopes, as allowing for different regression slopes produced very imprecise and nonsensical results, and also had lower AIC scores. The proper interpretation of the regression is thus as an average over the crosses. To avoid over-parameterization and to save computer time, we did not include any covariance components in this analysis and we assumed that all crosses had the same residual variance. The sons and daughters were treated separately and the regressions on sires and dams were also conducted separately.

\section{Statistical analysis}

The mixed-model analysis was conducted with PROC MIXED in SAS (version 6.12). As described in Searle et al. (1992), we based all estimates of variance components on restricted maximum likelihood (REML). This provides unbiased estimators that are superior to the usual ANOVA estimators on unbalanced designs. The estimation of within-population trait covariances follows the procedure of Searle et al. (1992: 382). The idea is to combine measurements of two or more traits in one data vector, include a random effect corresponding to each trait, and then estimate the variances and covariances between these random effects as in a standard univariate mixed-model analysis. The covariances between the residual effects can also be estimated in this design. Conditionally on an estimated variance structure, the fixed effects were estimated with generalized least squares that provide unbiased minimum-variance estimators. For estimation of fixed effects, AIC $(=2(-\log$ likelihood + number of parameters in model)) was used to select an optimal variance structure (see Tong 1990: 281-292 for discussion of AIC). The AIC was based on the residual likelihood. We also used AIC to decide whether the mean effects of the growth traits were best estimated in the multivariate or in separate univariate analyses. $F$-tests are all of type III (SAS Institute Inc. 1989). Estimates are given as estimate \pm standard error. For each trait, we evaluated the distribution of the residuals and plotted them against the model prediction. Visual inspection did not reveal any gross violation of normality and, despite rather large sample sizes, it was in most cases not possible to reject normality at $5 \%$ significance with a Kolmogorov $D$-test. We did not detect serious skew, kurtosis, or heteroscedasticity. On this basis, we report all results from analyses of untransformed data.

\section{Results}

\section{Phenotypic differences between populations}

Observations in the field indicate that there are large differences in body size among the three populations. Animals from Pinawa are small, those from Wolfe intermediate, and those from Toronto large. In Fig. 1 we present growth curves of cohorts of overwintered males followed through parts of the season in the field. This comparison shows clear size differences that cannot be due to differences in age structure or season. For example, in late April when virtually all males were in breeding condition, the average weight of Pinawa males was $33.0 \mathrm{~g}(\mathrm{SD}=4.14, N=48)$, while Wolfe males (from 1984) weighed $42.4 \mathrm{~g}(\mathrm{SD}=3.75, N=10)$, and Toronto males $52.0 \mathrm{~g}(\mathrm{SD}=6.58, N=43)$. Neither are the differences likely to be due to cycle phase differences, as the Toronto and Pinawa animals were obtained from peak populations, and the Wolfe animals were also from high-density conditions; although this latter population did not appear to be going through a pronounced cycle. The animals used in the breeding experiment are fairly representative of the differences observed in the field. Their sizes at the beginning and the end of the experiment are given in Table 3 . The initial weight differences among males are similar to those of Fig. 1. The experimental females show a similar pattern to that of the males.

The Pinawa females produced smaller litters than the others. The mean and standard deviations of litter size are given in Table 3, but, as these are potentially confounded by nonrandom mating of the populations,

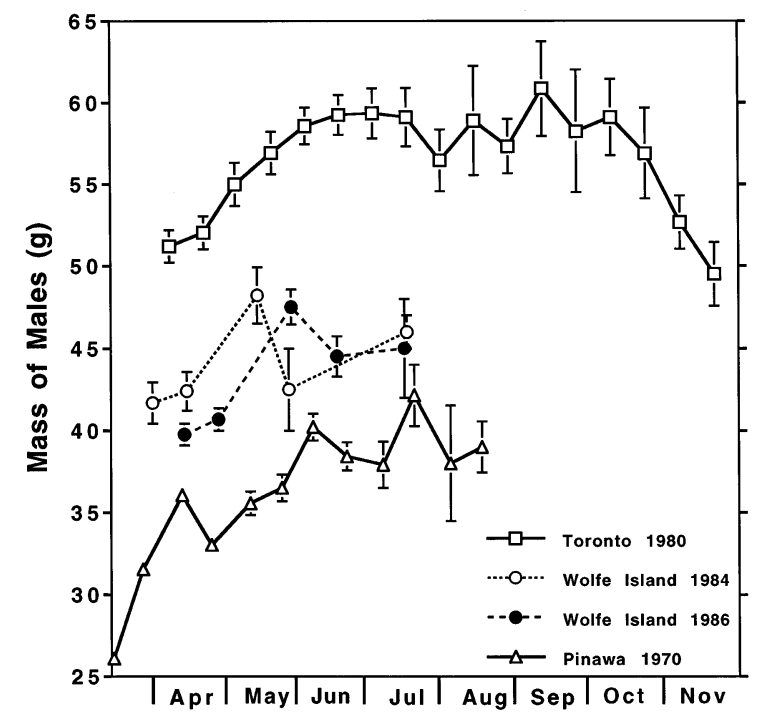

Fig. 1. Comparisons of mass changes $(\mathrm{g})$ in cohorts of males from field populations of Microtus pennsylvanicus. Toronto males are about $10-15 \mathrm{~g}$ heavier than the Wolfe males and 20 $\mathrm{g}$ heavier than the Pinawa males. These differences are roughly maintained over time. Standard errors are indicated by bars. 
Table 3. The parents, breeding and last weights are mean weights $(\mathrm{g})$ at the time breeding started and at the end of the experiment. The last weight of females was taken after the litter was weaned. None of the female weight measurements are therefore confounded by pregnancy or lactation. Litter size is mean litter size at birth and $N$ is number of individuals. Standard deviations are given in parentheses.

\begin{tabular}{lllll}
\hline Population & Breeding weight & Last weight & Litter size & $N$ \\
\hline Males & & & & \\
$\quad$ Toronto & $52.85(6.44)$ & $50.35(6.01)$ & $6.70(1.95)$ & 20 \\
$\quad$ Pinawa & $39.64(10.42)$ & $41.91(12.33)$ & $5.91(1.64)$ & 11 \\
$\quad$ Wolfe & $45.27(3.79)$ & $45.60(3.31)$ & $6.71(1.38)$ & 15 \\
Females & & & & \\
$\quad$ Toronto & $42.92(5.57)$ & $44.08(5.03)$ & $7.00(1.73)$ & 25 \\
$\quad$ Pinawa & $29.23(6.52)$ & $30.46(4.18)$ & $4.85(1.73)$ & 13 \\
$\quad$ Wolfe & $38.70(4.52)$ & $41.50(6.35)$ & $6.67(1.22)$ & 10 \\
\hline
\end{tabular}

we conducted an ANOVA to separate the effects of sire and dam. As expected, this revealed a small and statistically insignificant effect of the sire $\left(F_{2,42}=1.43, p=\right.$ $0.25)$. Controlling for the sire effect, the estimated mean litter sizes of the dams (using Wolfe sire as reference) are Pinawa: $4.07 \pm 0.75$, Wolfe: $6.23 \pm 0.60$, and Toronto: $6.49 \pm 0.47$. To see if the differences in litter size are reflections of differences in mother's size, we did a regression of litter size on mothers breeding weight controlling for the origin of the mother. The slope was $0.050 \pm 0.044 \mathrm{~g}^{-1}$. This is not sufficient to explain the smaller litter size of Pinawa females; to predict the difference from Toronto and Wolfe, respectively, slopes of $0.16 \mathrm{~g}^{-1}$ and $0.19 \mathrm{~g}^{-1}$ would have been required.

\section{Quantitative genetic differences in growth between populations}

In Fig. 2 estimated growth curves for the different crosses are presented. In Table 4 we present a decomposition of the variables into additive and maternal differences, and dominance interactions between the populations. The overall result is that differences between the crosses are very small relative to the natural phenotypic variation. Neither genetic nor maternal effects can explain more than a few percent of the phenotypic differences among populations. Particularly interesting is the lack of evidence for additive genetic effects. For both males and females, the additive genetic differences in growth are very small, inconsistent in direction, and never statistically significant. Furthermore, they are not consistent in direction with the observed phenotypic differences. In conclusion, the observed phenotypic differences cannot be explained as additive genetic effects.

There is little difference in maternal effects between the Wolfe and the Toronto animals, but, consistent with the small size of Pinawa mothers, their offspring show a tendency for slow growth before weaning. At least for males, this tendency is still visible at the end of the experiment and maternal effects may be a factor contributing to the small size of the Pinawa animals. However, it is conceivable that this is influenced by the experimentally altered litter sizes in the lab. In nature, Pinawa females may raise smaller litters and be better able to provide adequate resources for individual pups.

In absolute terms, the interaction effects are not large, but they show some interesting patterns. As can be seen from Fig. 2c and d, the Toronto by Wolfe crosses show some evidence of overdominance at weaning. Subsequently, they show consistent underdominance in growth and end up as somewhat underdominant. The dominance interaction between Toronto and Pinawa is less clear, but it indicates an opposite pattern where the young start out at weaning as slightly smaller than the pure breeds, and from then onwards they grow fast, and end up as overdominant (in Fig. 2e and $\mathrm{f}$, this is somewhat confounded by maternal effects).

\section{Within-population variation in growth}

Estimates of the variance components of the growth traits are given in Table 5. These estimates should be interpreted as averages of the variances in the different crosses after controlling for the mean effects.

There is evidence for substantial variation both within and among litters for all the growth traits and the levels are roughly similar for the four traits. The total variation is $7-8 \mathrm{~g}^{2}$ for all growth traits in females and $9-14 \mathrm{~g}^{2}$ for all growth traits in males. Among-litter variation in excess of the within-litter variation must be due to maternal or cage effects (see eq. 2). Assuming that the cage effect can be ignored, we have evidence for a substantial maternal variance component. For weight at weaning the fraction of the total within-population variation attributable to maternal effects must be at least $37 \%$ for females and $43 \%$ for males. For the subsequent growth traits this lower limit is smaller, but both G25 and G40 show evidence of a substantial maternal variance. The high fraction of variation among litters also puts an upper limit to the genetic effects. For weight at weaning there is an upper limit to 
the heritability of $62 \%$ for females and $57 \%$ for males, but the real value must be much smaller as this limit assumes a total absence of both special environmental and nonadditive genetic effects.

a)

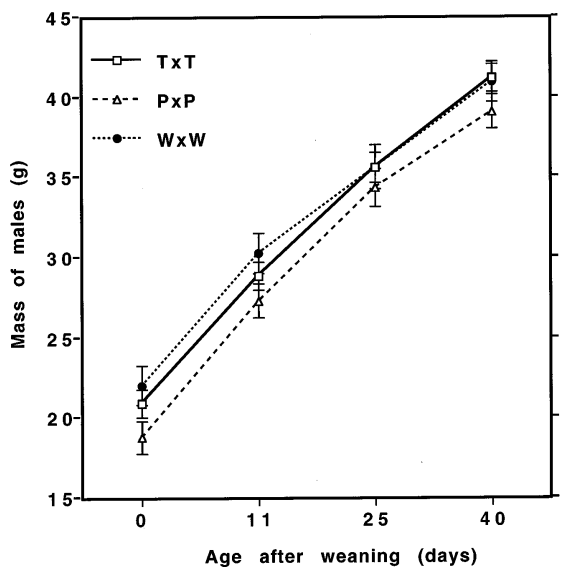

c)

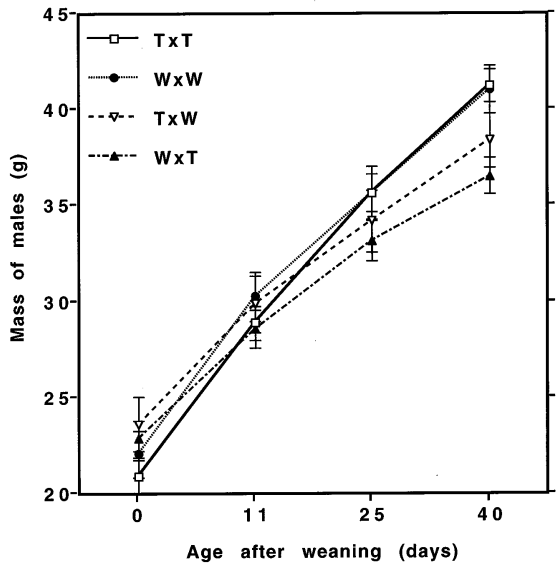

e)

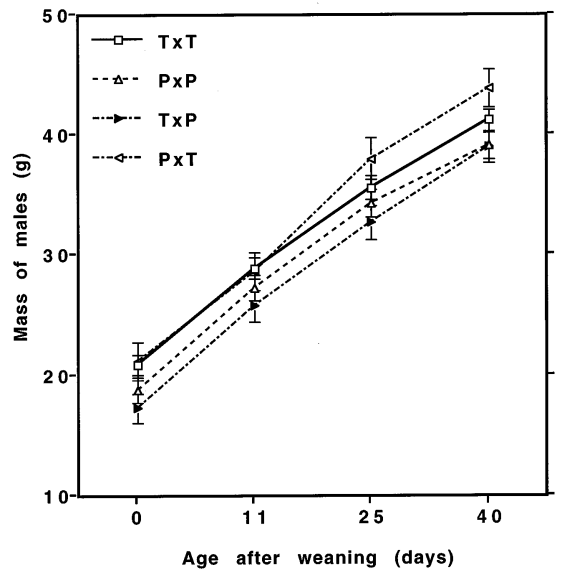

Estimates of correlations between growth traits (not shown) are relatively small given the close association between these traits. In particular, growth before weaning is relatively independent of later growth (between-

b)

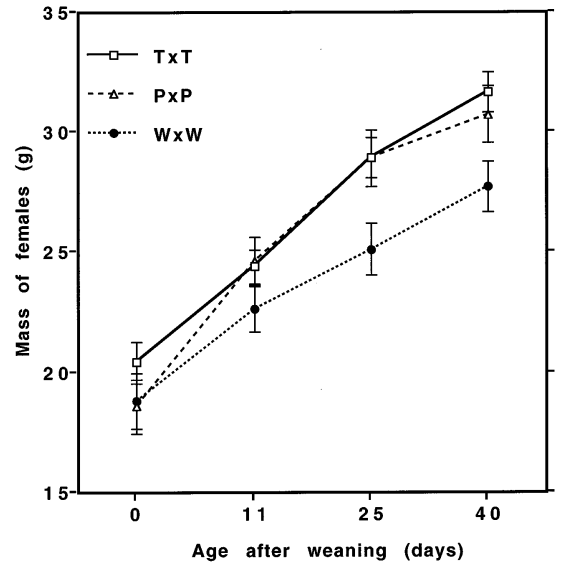

d)

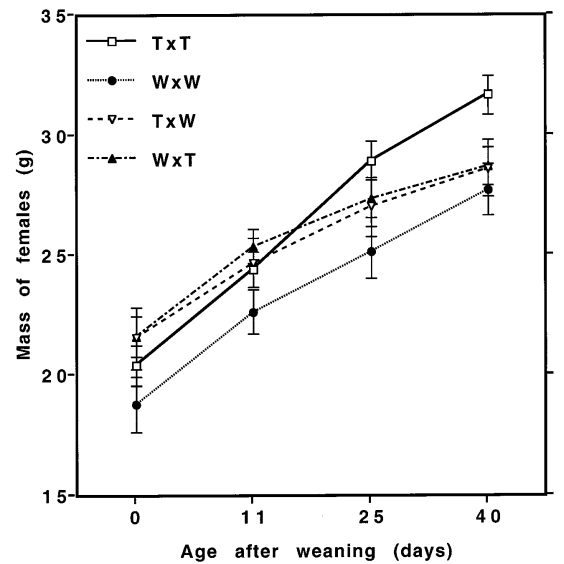

f)

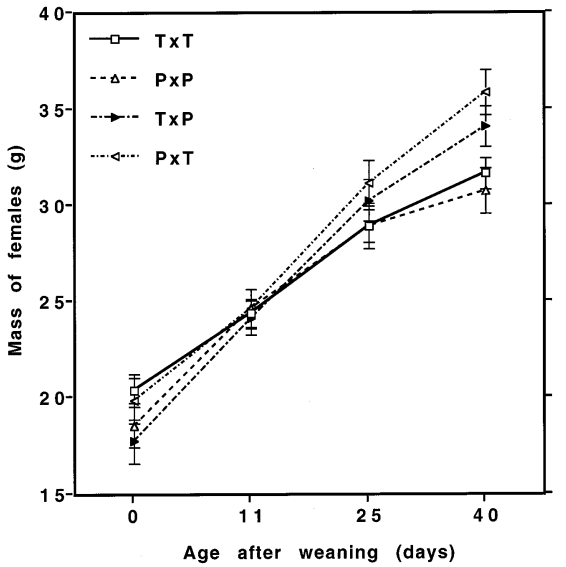

Fig. 2. Estimated growth curves of the $F_{1}$ 's from the seven crosses (see Table 2 for notation). In a) and b) the pure breeds are compared, in c) and d) the Toronto and Wolfe hybrids are compared with the pure breeds, and in e) and f) the Toronto and Pinawa hybrids are compared with the pure breeds. Males are a), c) and e) and females are b), d) and f). The estimates are based on a joint analysis of weight at weaning and the three growth rates (G11, G25 and G40). Error bars refer to standard error of the growth variables (i.e. the G-variables) and not the absolute weight at that stage. 
Table 4. Estimates $( \pm \mathrm{SE})$ of quantitative-genetic differences among populations: All estimates are in grams except age at maturity which is measured in days. The additive and maternal effects are expressed as contrasts between populations (i.e. T $\mathrm{P}$ is the difference between Toronto and Pinawa and so on). The additive difference is expressed as allelic effects (i.e. multiply by two to get the difference between two purebred individuals). The dominance effects are expressed as deviance of the cross from the expectation based on the additive and maternal effects ( $\mathrm{T}$ by $\mathrm{P}$ is the interaction between Toronto and Pinawa and so on). Despite the fact that individual comparisons are never statistically significant (at $p<0.05)$, the results do indicate a cross effect. For weight at weaning there is a statistically significant effect of cross for males $\left(F_{6,82}=3.60, p=0.003\right)$ and a marginal effect for females $\left(F_{6,82}=1.97, p=0.08\right)$. For subsequent growth until day 40 after weaning there is no significant effect for males $\left(F_{6,76}=1.53, p=0.18\right)$, but there is for females $\left(F_{6,72}=2.94, p=0.01\right)$. These tests are based on univariate analyses.

\begin{tabular}{|c|c|c|c|c|c|c|c|}
\hline \multirow[t]{2}{*}{ Trait } & \multicolumn{3}{|c|}{ Additive effects } & \multicolumn{2}{|c|}{ Maternal effects } & \multicolumn{2}{|c|}{ Dominance effects } \\
\hline & $\mathrm{T}-\mathrm{P}$ & $\mathrm{T}-\mathrm{W}$ & $P-W$ & $\mathrm{~T}-\mathrm{P}$ & $\mathrm{T}-\mathrm{W}$ & $\mathrm{T}$ by $\mathrm{P}$ & $\mathrm{T}$ by $\mathrm{W}$ \\
\hline \multicolumn{8}{|l|}{ Females: } \\
\hline Wwean & $-0.15 \pm 1.08$ & $0.79 \pm 1.05$ & $0.94 \pm 1.38$ & $1.41 \pm 1.21$ & $-0.68 \pm 1.16$ & $-0.68 \pm 1.08$ & $1.97 \pm 1.05$ \\
\hline G11 & $-0.20 \pm 0.92$ & $-0.49 \pm 0.85$ & $-0.29 \pm 1.14$ & $-1.32 \pm 0.99$ & $0.98 \pm 0.94$ & $0.56 \pm 0.92$ & $-0.72 \pm 0.85$ \\
\hline G25 & $-0.09 \pm 1.08$ & $1.19 \pm 0.99$ & $1.28 \pm 1.34$ & $0.40 \pm 1.17$ & $-0.37 \pm 1.10$ & $1.89 \pm 1.08$ & $-1.35 \pm 0.99$ \\
\hline G40 & $0.04 \pm 1.06$ & $0.20 \pm 0.97$ & $0.16 \pm 1.32$ & $0.66 \pm 1.15$ & $-0.47 \pm 1.08$ & $2.02 \pm 1.06$ & $-1.20 \pm 0.97$ \\
\hline W40 & $0.30 \pm 2.91$ & $2.20 \pm 2.67$ & $1.90 \pm 3.62$ & $1.04 \pm 3.16$ & $-0.59 \pm 2.96$ & $3.71 \pm 2.91$ & $-1.59 \pm 2.67$ \\
\hline Wmat & $-1.16 \pm 1.96$ & $-0.32 \pm 1.94$ & $0.84 \pm 2.46$ & $-0.37 \pm 2.00$ & $0.72 \pm 2.08$ & $1.47 \pm 1.96$ & $-0.47 \pm 1.94$ \\
\hline Amat & $-4.26 \pm 3.60$ & $-4.55 \pm 3.57$ & $-0.29 \pm 4.46$ & $-1.96 \pm 3.44$ & $2.58 \pm 3.73$ & $-1.17 \pm 3.60$ & $-6.05 \pm 3.57$ \\
\hline \multicolumn{8}{|l|}{ Males: } \\
\hline Wwean & $-0.92 \pm 1.20$ & $-0.20 \pm 1.13$ & $0.72 \pm 1.53$ & $2.88 \pm 1.43$ & $-1.81 \pm 1.31$ & $-0.57 \pm 1.20$ & $1.74 \pm 1.13$ \\
\hline G11 & $0.29 \pm 1.24$ & $0.17 \pm 1.17$ & $-0.12 \pm 1.59$ & $-0.55 \pm 1.49$ & $0.01 \pm 1.36$ & $-0.32 \pm 1.24$ & $-2.10 \pm 1.17$ \\
\hline G25 & $-1.36 \pm 1.35$ & $0.55 \pm 1.29$ & $1.91 \pm 1.73$ & $1.54 \pm 1.62$ & $-0.65 \pm 1.49$ & $1.27 \pm 1.35$ & $-1.62 \pm 1.29$ \\
\hline G40 & $0.62 \pm 1.24$ & $0.53 \pm 1.15$ & $-0.10 \pm 1.57$ & $-0.01 \pm 1.48$ & $-0.39 \pm 1.33$ & $0.87 \pm 1.24$ & $-1.68 \pm 1.15$ \\
\hline W40 & $-1.57 \pm 3.26$ & $0.73 \pm 3.03$ & $2.30 \pm 4.14$ & $4.24 \pm 3.92$ & $-2.99 \pm 3.53$ & $1.03 \pm 3.26$ & $-3.94 \pm 3.03$ \\
\hline Wmat & $0.83 \pm 1.35$ & $-0.33 \pm 1.28$ & $-1.17 \pm 1.74$ & $-0.03 \pm 1.64$ & $-0.52 \pm 1.50$ & $0.19 \pm 1.35$ & $0.35 \pm 1.28$ \\
\hline Amat & $2.19 \pm 2.51$ & $3.73 \pm 2.36$ & $1.55 \pm 3.22$ & $0.44 \pm 3.06$ & $-4.10 \pm 2.78$ & $-0.21 \pm 2.51$ & $4.49 \pm 2.36$ \\
\hline
\end{tabular}

litter correlations of weight at weaning with G11, which are larger than correlations with $\mathrm{G} 25$ and G40, are 0.42 for females and 0.16 for males). The between-litter covariances are also larger than the within-litter covariances suggesting either that maternal effects are important in determining trait correlations or that some proportionally more important component of the within-litter variance such as dominance, epistasis or special environmental effects are negatively correlated across traits.

Regressions of the growth traits on parental size are given in Table 6. As the growth traits are components of adult size, the regressions $(\times 2)$ give lower limits to the heritabilities. They can be seen as estimates of the additive genetic covariance between the growth traits and adult size. For weight at weaning the regression on mother is somewhat larger indicating that there are some maternal effects related to the size of the mother for this trait. Based on regression on sire, estimated lower limits for heritability are about $15 \%$ for weight at weaning. The growth traits show similar lower limits to heritability, and no consistent evidence of size-related maternal effects.

\section{Within-population variation in adult size}

The weight at day 40 after weaning is our best measure of adult size. The estimated between- and within-litter variances shown in Table 5 show that maternal effects remain important for adult size. Lower bounds of maternal variance for females and males are $30 \%$ and
$14 \%$, respectively, and upper limits to heritabilities are $70 \%$ and $86 \%$, respectively.

The parent-offspring regressions in Table 6 indicate very high heritabilities for adult size. If we estimate heritability as twice the father-son and mother-daughter regression of offspring weight at day 40 on parents last weight in lab, we get $h^{2}=0.84$ for the males and $h^{2}=0.88$ for the females. Regression on parent's breeding weight or use of midparent regressions also give very high heritabilities. These values seem inconsistent with the estimates from the sib analyses. This discrepancy is due to higher levels of phenotypic variation among the offspring than among the parents. The variance of parent's last weight after controlling for cross are $40.86 \mathrm{~g}^{2}$ for fathers and $25.37 \mathrm{~g}^{2}$ for mothers. This may be compared with $73.97 \mathrm{~g}^{2}$ for male and 54.10 $\mathrm{g}^{2}$ for female offspring at day 40 . The parent-offspring estimates of heritability therefore indicate that the additive genetic variance is $34.32 \mathrm{~g}^{2}$ for males and $22.33 \mathrm{~g}^{2}$ for females, and this is consistent with the sib analysis. By further assuming that nonadditive effects are absent, the offspring variation among males may be decomposed into $46.6 \%$ additive, $33.8 \%$ maternal and $19.8 \%$ special environmental effects. For females we find $41.3 \%$ additive, $45.5 \%$ maternal and $13.2 \%$ special environmental effects.

This reconciliation of the parent-offspring and sib analyses leaves one question unanswered. Why are the offspring more phenotypically variable than their parents? Specifically, our results indicate that the excess variation is due to maternal effects. Why is there less 
maternal variation in the parents? One possibility starts with the fact that the parental size is measured in older animals. It may be that the maternal effects primarily affects growth rates and that the animals tend to home in on their genetically determined target size if given enough time. This is consistent with our observation of more maternal variance at weaning than for subsequent growth.

\section{Age and size at maturity}

We analyzed age and size of maturity together with weight at weaning in a multivariate sib-sib analysis. Weight at weaning was included to investigate the relationship between maturation and early growth. Unfortunately, many females did not mature in the lab. This may possibly be an artifact of the females being raised in isolation from males after weaning, as female maturation may depend on proximity to males. Only animals that did mature are included in the analysis. Hence, results for females should be taken with a large grain of salt.

From Table 4 we see that the genetic and maternal differences in weight at maturity between populations are very small, typically less than a gram, and not consistent with the differences in weight at day 40 . Neither can age at maturity be said to differ much among populations.

However, the between-litter components of variation reported in Table 5 indicate a component of additive genetic or maternal variation within populations for these traits. This can also be seen from the parent-offspring regressions in Table 6. Age of maturity in males is negatively correlated with size of sire indicating that there is additive genetic covariance between age of maturity and size. This negative covariance means that genetically large males also mature early. This sire effect is not seen in females, but female maturation is negatively correlated with size of mother, so that daughters of large mothers mature earlier. There is also a very strong negative between-litter component of covariance between age and size of maturity (for males, between-litter correlation is -0.73 and the within-litter correlation is 0.08). Litters that mature early are also composed of individuals that are large at maturation. This must involve maternal effects and is consistent with a strong between-litter component of covariance between the maturation variables and weaning size (not shown).

\section{Discussion}

The major result of our analysis is that geographic size and growth variation in meadow voles could not be accounted for by genetic differences. This stands in striking contrast to the within-population variation which is dominated by additive genetic and maternal sources of variance; each explaining very roughly $40 \%$ of the variation. This raises the question of why there is so little genetic diversification of the populations despite the demonstrable evolvability of the traits. Clearly, the populations experience different environments that affect their size in very different ways. On this basis it seems unlikely that optimal size is the same in these three populations. The most obvious explanation is that there is sufficient gene flow to prevent local adaptation. In the case of the Pinawa population we see this as extremely unlikely. The distance form Pinawa to Toronto is $1440 \mathrm{~km}$ and the Pinawa population is sufficiently distinct to have been placed in a separate subspecies (M. p. drummondii as opposed to $M . p$. pennsylvanicus for the Ontario populations). The distinction between a central and an eastern population is supported by extensive mtDNA sequence divergence; the average estimated nucleotide divergence between the central Pinawa population and the eastern Ontario population is $3.90 \%$ which may correspond to divergence on the order of 1 M.Y.B.P. (Plante et al. 1989b). However, this sequence divergence suggesting long-term isolation in time may possibly be an artifact caused by mtDNA introgression into one of the populations from a third species (Dowling and Secor 1997). On the other hand, Plante et al. (1989a, b) also demonstrated extensive mtDNA diversity within the eastern population that is not closely tied to geography. They suggest that local populations of meadow voles may be regularly mixed

Table 5. Average within-population variances $( \pm \mathrm{SE})$. Between-litter variances are denoted $\sigma_{b l}^{2}$, and within-litter variances are denoted $\sigma_{w l}^{2}$. Variances significantly different from zero at $p<0.05$ (Wald tests) are indicated by an asterisk.

\begin{tabular}{|c|c|c|c|c|}
\hline & \multicolumn{2}{|l|}{ Females } & \multicolumn{2}{|l|}{ Males } \\
\hline & $\sigma_{b l}^{2}$ & $\sigma_{w l}^{2}$ & $\sigma_{b l}^{2}$ & $\sigma_{w l}^{2}$ \\
\hline Wwean & $5.79 \pm 1.63^{*}$ & $2.64 \pm 0.42 *$ & $6.68 \pm 1.81^{*}$ & $2.69 \pm 0.42^{*}$ \\
\hline G11 & $2.89 \pm 1.03^{*}$ & $4.13 \pm 0.65^{*}$ & $5.68 \pm 1.97 *$ & $6.66 \pm 1.05^{*}$ \\
\hline G25 & $4.85 \pm 1.47^{*}$ & $2.87 \pm 0.47^{*}$ & $7.25 \pm 2.36^{*}$ & $6.62 \pm 1.06^{*}$ \\
\hline G40 & $4.57 \pm 1.43^{*}$ & $2.96 \pm 0.49^{*}$ & $6.61 \pm 1.89^{*}$ & $3.27 \pm 0.53^{*}$ \\
\hline W40 & $35.77 \pm 10.60^{*}$ & $18.33 \pm 3.05^{*}$ & $42.15 \pm 13.12 *$ & $31.82 \pm 5.14 *$ \\
\hline Wmat & $8.38 \pm 5.25$ & $26.93 \pm 5.54 *$ & $6.02 \pm 2.29^{*}$ & $9.08 \pm 1.47 *$ \\
\hline Amat & $3.04 \pm 28.39$ & $142.8 \pm 33.75^{*}$ & $16.08 \pm 7.79 *$ & $43.00 \pm 6.97 *$ \\
\hline
\end{tabular}


Table 6. Parent-offspring regressions: Shown are regression slopes $( \pm \mathrm{SE})$ of offspring traits on the weights of parents at time of breeding and at end of the experiment. Weight at day 40 (W40) is the offspring trait most closely related to the parental weights. Heritability of size can be estimated as twice these regression slopes. For the other traits, the regressions are better interpreted in terms of covariances with size. Mean effects of cross and unequal family sizes are controlled for. Regressions significantly different from zero at $p<0.05$ are indicated with an asterisk.

\begin{tabular}{|c|c|c|c|c|}
\hline & \multicolumn{2}{|l|}{ Sire } & \multicolumn{2}{|l|}{ Dam } \\
\hline & Breeding weight & Last weight & Breeding weight & Last weight \\
\hline \multicolumn{5}{|l|}{ Females: } \\
\hline Wwean & $0.07 \pm 0.06$ & $0.08 \pm 0.06$ & $0.25 \pm 0.06^{*}$ & $0.20 \pm 0.08^{*}$ \\
\hline G11 & $0.12 \pm 0.05^{*}$ & $0.11 \pm 0.05^{*}$ & $0.08 \pm 0.06$ & $0.04 \pm 0.07$ \\
\hline G25 & $0.12 \pm 0.06^{*}$ & $0.14 \pm 0.06^{*}$ & $0.16 \pm 0.07 *$ & $0.14 \pm 0.08$ \\
\hline G40 & $0.15 \pm 0.06^{*}$ & $0.16 \pm 0.06^{*}$ & $0.07 \pm 0.07$ & $0.07 \pm 0.08$ \\
\hline W40 & $0.48 \pm 0.15^{*}$ & $0.51 \pm 0.15^{*}$ & $0.56 \pm 0.18^{*}$ & $0.44 \pm 0.20^{*}$ \\
\hline Wmat & $0.31 \pm 0.11^{*}$ & $0.34 \pm 0.11^{*}$ & $0.25 \pm 0.14$ & $0.17 \pm 0.16$ \\
\hline Amat & $0.04 \pm 0.24$ & $0.06 \pm 0.25$ & $-0.24 \pm 0.30$ & $-0.54 \pm 0.31$ \\
\hline \multicolumn{5}{|l|}{ Males: } \\
\hline Wwean & $0.07 \pm 0.07$ & $0.07 \pm 0.07$ & $0.22 \pm 0.07^{*}$ & $0.14 \pm 0.08$ \\
\hline G11 & $0.12 \pm 0.07$ & $0.09 \pm 0.07$ & $0.06 \pm 0.08$ & $-0.05 \pm 0.09$ \\
\hline G25 & $0.05 \pm 0.08$ & $0.09 \pm 0.08$ & $0.19 \pm 0.08^{*}$ & $0.12 \pm 0.10$ \\
\hline G40 & $0.15 \pm 0.07 *$ & $0.15 \pm 0.07^{*}$ & $-0.01 \pm 0.08$ & $0.02 \pm 0.09$ \\
\hline W40 & $0.40 \pm 0.17 *$ & $0.41 \pm 0.18^{*}$ & $0.46 \pm 0.19 *$ & $0.21 \pm 0.23$ \\
\hline Wmat & $0.11 \pm 0.07$ & $0.05 \pm 0.08$ & $0.17 \pm 0.08^{*}$ & $0.01 \pm 0.10$ \\
\hline Amat & $-0.31 \pm 0.13^{*}$ & $-0.30 \pm 0.14 *$ & $-0.42 \pm 0.14^{*}$ & $-0.19 \pm 0.18$ \\
\hline
\end{tabular}

into large and almost panmictic populations as a result of population density fluctuations and dispersal over large areas. At $240 \mathrm{~km}$ apart, Toronto and Wolfe are within this eastern area of postulated mixing. Although Wolfe is an island, both the molecular diversity (Plante et al. 1989a, b) and Lomolino's (1982, 1984) observations of dispersal over ice indicate some gene flow from the mainland. In conclusion, it is not unlikely that gene flow contributes to the similarity of the Toronto and Wolfe samples, whereas it is almost certainly not a factor with respect to the Pinawa population.

The deep mitochondrial split also rules out common ancestry as a cause of similarity, but the possibility remains that relatively recent ancestors of the populations lived in more similar environments. Though $\mathrm{Mi}$ crotus pennsylvanicus may have originated in the Eastern boreal refugium (DeBry 1992), it is not reported in the Beringian refugium (Hoffman and Koeppl 1985), and the populations are unlikely to have lived in their present environments for more than 10000 years (e.g. Pielou 1991). Still, with the level of additive genetic variation found within our populations, considerable genetic differentiation can easily be accommodated within this time frame both by selection and by random genetic drift.

A speculative explanation of these observations is that the populations reflect different positions on a similar norm of reaction that is itself optimized over an environmental range likely to be experienced by this species. This means that the populations must experience a similar range of temporal or spatial variation of the environment that can provide the selective pressures necessary to maintain a reaction norm. The possibility of regular dispersal events over large areas, as suggested by Plante et al. (1989a, b), may be a factor increasing the range of spatial variation regularly experienced by the population. Spatial or temporal variation in food availability, population density and climate are candidate ecological factors that may produce variation in size-related fitness. These factors are known to influence size in rodents, and may be implicated in general ecogeographic patterns. They are also likely to be variable on fine spatial and temporal scales. It is noteworthy that the small Pinawa animals come from a region with much lower primary production and population densities, as well as a much colder climate.

Meadow voles decrease in size when the climate gets colder (McNab 1971, Snell and Cunnison 1983). Our results suggest that this effect is not genetic and may therefore be mediated through a reaction norm also expressed within populations. There are several candidates. Temperature is known to affect the growth of nestlings (Daketse and Marinet 1977), and Yoccoz et al. (1993) favored this explanation for the large phenotypic increase in size of $M$. epiroticus on Svalbard as compared with a mainland population from Finland. However, this explanation is not applicable in our case as meadow voles gets smaller, not larger, in cold climates and also seems to be most sensitive to winter temperature as adults (Snell and Cunnison 1983). The climatic response may also be related to the seasonal changes in body size (Brown 1973, Iverson and Turner 1974). Individual meadow voles lose weight during autumn, but this is not due to poor nutrition and may rather be a response cued to a shortening photoperiod (Pistole and Cranford 1982, Dark and Zucker 1986). The reduction of size in the winter season is believed to be an adaptation to reduce total energy needs in a nutritionally poor or metabolically challenging winter environment (Stenseth 1978, Chappell 1980, Snell and 
Cunnison 1983, Hansson 1990). Such a reaction norm may make animals from more northern latitudes smaller through a reduced growing season, and this may be adaptively maintained through the advantage of smaller size in the generally longer and colder winter. However, this hypothesis cannot explain why the size reduction seems to be better explained by extreme winter temperature than by latitude, and it is also doubtful whether the relatively mild climatic differences between Wolfe and Toronto can explain the difference between these populations.

An interesting possibility is that adaptive size plasticity is maintained by the large, and often cyclic, density fluctuations that are common in voles (see Stenseth and Ims 1993 for review). Early on, it was discovered that the voles are larger at the peak of the cycle (Chitty and Chitty 1962, Krebs and Myers 1974, Boonstra and Krebs 1979, Taitt and Krebs 1985), and it has been suggested that changes in size along with associated changes in behavior and life history may be the very cause of the cycles (Chitty 1967). This is unlikely for both theoretical (Stenseth 1981) and empirical reasons (Gaines 1985, Lidicker and Ostfeld 1991, Boonstra et al. 1994). Krebs (1979) and Agrell et al. (1992) have furthermore demonstrated that size varies with population density also in noncyclic vole populations. The density-related size changes are clearly phenotypic responses (e.g. Lidicker and Ostfeld 1991), and for our Toronto population, Boonstra and Boag (1987) demonstrated that the cyclic size changes were too large to be accounted for by realistic selection gradients and levels of additive genetic variation. The adaptive basis of these size changes may be related to an advantage of large animals under competitive high-density conditions (Boonstra and Krebs 1979, Adler and Levins 1994). High density may also alter selection on size by altering predation pressure or by inducing large-scale dispersal and utilization of different habitat types.

Alternatively, density-related size changes may be an indirect effect of a reaction norm that is maintained for other reasons, such as a general plasticity in relation to food availability. The phenotypic response to food and nutritional quality can strongly influence size in rodents (Hansson and Jaarola 1989, Agrell et al. 1992, Boutin 1992). The growth of offspring is affected by maternal nutrition (Mattingly and McClure 1985), but this effect is complicated as poor maternal nutrition may also lead to smaller litters and better growth of individual offspring (Falconer 1965, Millar 1983). Patton and Brylski (1987) have demonstrated nutrition to be a cause of variation across different habitats on large geographical scales in pocket gophers of the genus Thomomys.

Although additive genetic variation in size and growth is probably usually present within local populations, several studies of voles have indicated that maternal sources of variation are more important (Anderson 1975, see also Krebs 1979, Boonstra and Boag 1987,
Boonstra and Hochachka 1997). Maternal effects are also known to be an essential component of variance in the growth of lab mice (Atchley and Newman 1989). Our results add to this by demonstrating that some $40 \%$ of the variation in weight at day 40 may be due to maternal effects. For early growth and maturation, maternal effects seem to be even more important, an effect also seen in lab mice (e.g., Riska et al. 1984) and in other studies of natural populations such as Roth and Klein (1986) on Peromyscus. The young of a good mother are clearly able to start reproducing much earlier and, due to their larger size, they may be capable of bearing larger litters and acquiring better territories. The importance of maternal effects is consistent with the earlier study of the Toronto population by Boonstra and Boag (1987, Boag and Boonstra 1988). Boonstra (1994) has suggested that the density-related size changes may be mediated through maternal effects related to the age of the mother. However, despite the importance of maternal variance within populations, there was little evidence of maternal variation among populations in our study. Population differences due to genetically determined maternal effects can therefore be ruled out. However, the hypothesis that the small size of the Pinawa animals is due to environmentally determined maternal effects cannot be rejected as the Pinawa parents were not raised in their natural environment.

In conclusion, size is unlikely to be genetically constrained in the meadow vole, as there is abundant additive genetic variation and probably not strong genetic correlations among the growth variables. Clearly, the constraints that keep these populations genetically similar are not themselves genetic. Rather they are selective, and must be found in a detailed study of the species' phenotypic plasticity and in its environment with a special eye to the population dynamics on large temporal and spatial scales.

Acknowledgements - We thank Josef Serensits, Ian Craine, and Ken Fukumoto for helping with the field and lab aspects of this study, Steve Mihok for providing the Pinawa animals, Mark Engstrom for discussions, and Karl Fredga, Rolf A. Ims, Anssi Saura, Nils Chr. Stenseth and Nigel G. Yoccoz for discussions and comments on the paper. We thank Natural Sciences and Engineering Research Council of Canada for providing research funds to RB, a postdoctoral grant from the Univ. of Oslo, through Nils Chr. Stenseth, for supporting $\mathrm{TFH}$, and the Center for Advanced Study, Norwegian Academy of Science and Letters for providing financial support, solitude, coffee, and computing and writing facilities.

\section{References}

Adler, G. H. and Levins, R. 1994. The island syndrome in rodent populations. - Q. Rev. Biol. 69: 473-490.

Agrell, J., Erlinge, S., Nelson, J. and Sandell, M. 1992. Body weight and population dynamics: cyclic demography in a noncyclic population of the field vole (Microtus agrestis). Can. J. Zool. 70: 494-501. 
Anderson, J. L. 1975. Phenotypic correlations among relatives and variability in reproductive performance in populations of the vole Microtus townsendii. - PhD thesis, Univ. of British Columbia, Canada.

Atchley, W. R. and Newman, S. 1989. A quantitative-genetics perspective on mammalian development. - Am. Nat. 134: 486-512.

Berry, R. J. 1996. Small mammal differentiation on islands. Philos. Trans. R. Soc. Lond. B 351: 753-764.

Boag, P. T. and Boonstra, R. 1988. Quantitative genetics of life history traits in meadow voles (Microtus pennsylvanicus). - In: Boyce, M. (ed.), Evolution of life histories of mammals: theory and pattern. Yale Univ. Press, New Haven, CT, pp. 149-168.

Bonser, S. P. and Reader, R. J. 1995. Plant competition and herbivory in relation to vegetation biomass. - Ecology 76 : 2176-2183.

Boonstra, R. 1985. Demography of Microtus pennsylvanicus in southern Ontario: enumeration versus Jolly-Seber estimation compared. - Can. J. Zool. 63: 1174-1180.

Boonstra, R. 1994. Population cycles in microtines: the senescence hypothesis. - Evol. Ecol. 8: 196-219.

Boonstra, R. and Krebs, C. J. 1979. Viability of large and small sized adults in fluctuating vole populations. - Ecology 60: $567-573$.

Boonstra, R. and Rodd, F. H. 1983. Regulation of breeding density in Microtus pennsylvanicus. - J. Anim. Ecol. 52: 757-780.

Boonstra, R. and Boag, P. T. 1987. A test of the Chitty Hypothesis: inheritance of life-history traits in meadow voles Microtus pennsylvanicus. - Evolution 41: 929-947.

Boonstra, R. and Boag, P. T. 1992. Spring declines in Microtus pennsylvanicus and the role of steroid hormones. - J. Anim. Ecol. 61: 339-352.

Boonstra, R. and Hochachka, W. M. 1997. Maternal effects and additive genetic inheritance in the collared lemming (Dicrostonyx groenlandicus). - Evol. Ecol. 11: 169-182.

Boonstra, R., Hochachka, W. M. and Pavone, L. 1994. Heterozygosity, aggression, and population fluctuations in meadow voles (Microtus pennsylvanicus). - Evolution 48: $1350-1363$

Boutin, S. 1992. Food supplementation experiments with terrestrial vertebrates: patterns, problems, and the future. Can. J. Zool. 68: 203-220.

Brown, E. B. III. 1973. Changes in patterns of seasonal growth of Microtus pennsylvanicus. - Ecology 54: 1103-1110.

Brown, J. H. and Lee, A. K. 1969. Bergmann's rule and climate adaptation in woodrats (Neotoma). - Evolution 23: $329-338$.

Canadian Climate Normals. 1993. Vol. 2. Prairie Provinces, Volume 4. Ontario. - Canadian Communication Group Publ., Ottawa, Canada.

Chappell, M. A. 1980. Thermal energetics and thermoregulatory costs of small arctic mammals. - J. Mammal. 61 $278-291$.

Charnov, E. 1993. Life history invariants. - Oxford Univ. Press, Oxford.

Chitty, D. 1967. The natural selection of self-regulatory behavior in animal populations. - Proc. Ecol. Soc. Aust. 2. $51-78$.

Chitty, H. and Chitty, D. 1962. Body weight in relation to population phase in Microtus agrestis. - Symp. Theriologicum, Brno. 1960: 77-86.

Daketse, M.-J. and Marinet, L. 1977. Effect of temperature on the growth and fertility of the field-vole, Microtus arvalis, raised in different daylength and feeding conditions. Ann. Biol. Anim. Biochim. Biophys. 17: 713-721.

Dark, J. and Zucker, I. 1986. Photoperiodic regulation of body mass and fat reserves in the meadow vole. - Physiol. Behav. 38: $851-854$

DeBry, R. W. 1992. Biogeography of new world taiga-dwelling Microtus (Mammalia: Arvicolidae): a hypothesis test that accounts for phylogenetic uncertainty. - Evolution 46: $1347-1357$.
Dowling, T. E. and Secor, C. L. 1997. The role of hybridization and introgression in the diversification of animals. Annu. Rev. Ecol. Syst. 28: 593-619.

Ebenhard, T. 1990. A colonization strategy in field voles (Microtus agrestis): reproductive traits and body size. Ecology 71: 1833-1848.

Falconer, D. S. 1965. Maternal effects and selection response. - In: Geerts, S. J. (ed.), Proceedings of the XI International Congress on Genetics Today, 3: 763-774.

Foster, J. B. 1964. Evolution of mammals on islands. Nature 202: 234-235.

Gaines, M. 1985. Genetics. - In: Tamarin, R. H. (ed.), Biology of New World Microtus. American Society of Mammalogists, Spec. Publ. 8: 845-883.

Geist, V. 1987. Bergmann's rule is invalid. - Can. J. Zool. 65: $1035-1038$.

Hansson, L. 1985. Geographic differences in bank voles Clethrionomys glareolus in relation to ecogeographic rules and possible demographic and nutritive strategies. - Ann. Zool. Fenn. 22: 319-328.

Hansson, L. 1990. Ultimate factors in the winter weight depression of small mammals. - Mammalia 54: 397-404.

Hansson, L. and Jaarola, M. 1989. Body size related to cylicity in microtines: dominance behaviour or digestive efficiency. - Oikos 55: 356-364.

Harvey, P. H., Read, A. F. and Promislow, D. E. L. 1989. Life history variation in placental mammals: unifying the data with theory. - In: Partridge, L. (ed.), Oxford surveys in evolutionary biology 6: 13-31.

Hoffman, R. S. and Koeppl, J. W. 1985. Zoogeography. - In: Tamarin, R. H. (ed.), Biology of New World Microtus. American Society of Mammalogists, Spec. Publ. 8: 84-115.

Ims, R. A. 1997. Determinants of geographic variation in growth and reproductive traits in the root vole. - Ecology 78: $461-470$.

Iverson, S. L. and Turner, B. N. 1974. Winter weight dynamics in Microtus pennsylvanicus. - Ecology 55: 1030-1041.

James, F. C. 1983. Environmental component of morphological differentiation in birds. - Science 221: 184-186.

Kozlowski, J. and Weiner, J. 1997. Interspecific allometries are by-products of body size optimization. - Am. Nat. 149: $352-380$

Krebs, C. J. 1979. Dispersal, spacing behavior, and genetics in relation to population fluctuations in the vole Microtus townsendii. - Fortschr. Zool. 25: 61-77.

Krebs, C. K. and Myers, J. H. 1974. Population cycles in small mammals. - Adv. Ecol. Res. 8: 267-399.

Krebs, C. K. and Wingate, I. 1985. Population fluctuations in the small mammals of the Kluane region, Yukon territory. - Can. Field-Nat. 99: 51-61.

Krebs, C. K., Gaines, M. S., Keller, B. L. et al. 1973. Population cycles in small rodents. - Science 179: 35-41.

Lidicker, W. Z., Jr. and Ostfeld, R. S. 1991. Extra-large body size in California voles: causes and fitness consequences. Oikos 61: 108-121.

Lomolino, M. V. 1982. Species-area and species-distance relationships of terrestrial mammals in the Thousand Island Region. - Oecologia 54: 72-75

Lomolino, M. V. 1984. Immigrant selection, predation, and the distributions of Microtus pennsylvanicus and Blarina brevicauda on islands. - Am. Nat. 123: 468-483.

Lomolino, M. V. 1985. Body size of mammals on islands: the island rule reexamined. - Am. Nat. 125: 310-316.

Lynch, C. B. 1992. Clinal variation in cold adaptation in Mus domesticus: verification of predictions from laboratory populations. - Am. Nat. 139: 1219-1236.

Lynch, C. B. 1994. Evolutionary inferences from genetic analyses of cold adaptation in laboratory and wild populations of the house mouse. - In: Boake, C. R. B. (ed.), Quantitative genetic studies of behavioral evolution. Univ. of Chicago Press, Chicago, pp. 278-304.

Lynch, M. and Walsh, B. 1998. Genetics and analysis of quantitative traits. - Sinauer, Sunderland, MA. 
Mattingly, D. K. and McClure, P. A. 1985. Energy allocation during lactation in cotton rats (Sigmodon hispidus) on a restricted diet. - Ecology 66: 928-937.

Mayr, E. 1963. Animal species and evolution. - Belknap Press, Cambridge MA.

McGuire, B. and Novak, M. 1984. A comparison of maternal behaviour in the meadow vole (Microtus pennsylvanicus), prairie vole (M. ochrogaster) and pine vole ( $M$. pinetorum). - Anim. Behav. 32: 1132-1141.

McNab, B. K. 1971. On the ecological significance of Bergmann's rule. - Ecology 52: 845-852.

Mihok, S. 1984. Life history profiles of boreal meadow voles (Microtus pennsylvanicus). - Spec. Publ. Carnegie Mus. Nat. Hist. 10: $91-102$.

Mihok, S. and Boonstra, R. 1992. Breeding performance in captivity of meadow voles (Microtus pennsylvanicus) from decline- and increase-phase populations. - Can. J. Zool. 70: $1561-1566$.

Mihok, S., Turner, B. N. and Iverson, S. L. 1985. The characterization of vole population dynamics. - Ecol Monogr. 55: 399-420.

Mihok, S., Lawton, T. and Schwartz, B. 1988. Fates and movements of meadow voles (Microtus pennsylvanicus) following a population decline. - Can. J. Zool. 66: 323-328.

Millar, J. S. 1983. Negative maternal effects in Peromyscus maniculatus. - J. Mammal. 64: 540-543.

Morrison, P., Dieterich, R. and Preston, D. 1977. Body growth in sixteen rodent species and subspecies maintained in laboratory colonies. - Physiol. Zool. 50: 294-310.

Niewiarowski, P. H. and Roosenburg, W. 1993. Reciprocal transplant reveals sources of variation in growth rates of the lizard Sceloporus undulatus. - Ecology 74: 1992-2002.

Patton, J. L. and Brylski, P. V. 1987. Pocket gophers in alfalfa fields: causes and consequences of habitat-related body size variation. - Am. Nat. 130: 493-506.

Pielou, E. C. 1991. After the Ice Age: the return of life to glaciated North America. - Univ. Chicago Press, Chicago.

Pistole, D. H. and Cranford, J. A. 1982. Photoperiodic effects on growth in Microtus pennsylvanicus. - J. Mammal. 63: $547-553$.

Plante, Y., Boag, P. T. and White, B. N. 1989a. Microgeographic variation in mitochondrial DNA of meadow voles (Microtus pennsylvanicus) in relation to population density. - Evolution 43: 1522-1537.
Plante, Y., Boag, P. T. and White, B. N. 1989b. Macrogeographic variation in mitochondrial DNA of meadow voles (Microtus pennsylvanicus). - Can. J. Zool. 67: 158-167.

Ralls, K. and Harvey, P. H. 1985. Geographic variation in size and sexual dimorphism of North American weasels. Biol. J. Linn. Soc. 25: 119-167.

Riska, B., Atchley, W. R. and Rutledge, J. J. 1984. A genetic analysis of targeted growth in mice. - Genetics 107: 79 101

Roth, V. L. and Klein, M. S. 1986. Maternal effects on body size of large insular Peromyscus maniculatus: evidence from embryo transfer experiments. - J. Mammal. 67: 37-45.

SAS Institute Inc. 1989. SAS/STAT User's guide, Ver. 6, 4th ed., vol. 1. - SAS Inst., Inc., Cary, NC.

Searle, S. R., Casella, G. and McCulloch, C. E. 1992. Variance components. - Wiley, New York.

Smith, F. A., Betancurt, J. L. and Brown, J. H. 1995. Evolution of body size in the Woodrat over the past 25000 years of climate change. - Science 270: 2012-2014.

Snell, R. R. and Cunnison, K. M. 1983. Relation of geographic variation in the skull of Microtus pennsylvanicus to climate. - Can. J. Zool. 61: 1232-1241.

Sorci, G., Clobert, J. and Belichon, S. 1996. Phenotypic plasticity of growth and survival in the common lizard Lacerta vivipara. - J. Anim. Ecol. 65: 781-790.

Stenseth, N. C. 1978. Energy balance and the Malthusian parameter, $m$, of grazing small rodents. - Oecologia 32: $37-55$.

Stenseth, N. C. 1981. On Chitty's theory for fluctuating populations: the importance of genetic polymorphism in the generation of regular density cycles. - J. Theor. Biol. 90: $9-36$.

Stenseth, N. C. and Ims, R. A. 1993. The biology of lemmings. - Academic Press, London.

Taitt, M. J. and Krebs, C. J. 1985. Population dynamics and cycles. - In: Tamrarin, R. H. (ed.), Biology of New World Microtus. American Society of Mammalogists, Spec. Publ. 8: $567-620$.

Tong, H. 1990. Nonlinear time series analysis. - Oxford Science Publ., New York.

Yoccoz, N. G., Ims, R. A. and Steen, H. 1993. Growth and reproduction in island and mainland populations of the vole Microtus epiroticus. - Can. J. Zool. 71: 2518-2527. 